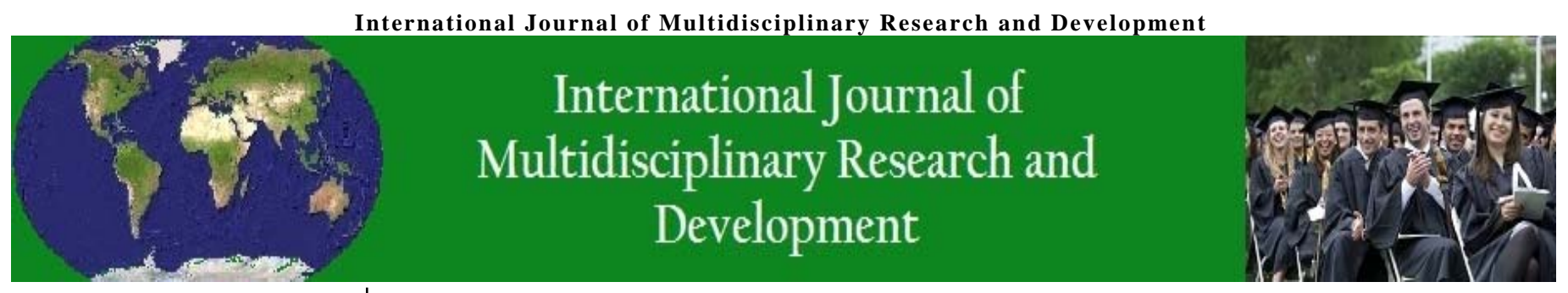

Volume :2, Issue :4, 606-614 April 2015

www.allsubjectjournal.com e-ISSN: 2349-4182

p-ISSN: 2349-5979

Impact Factor: 3.762

Fahareen-Binta-Mosharraf

Lecturer, Microbiology program Department of Mathematics and Natural Sciences BRAC University, 66 Mohakhali Dhaka,

Bangladesh

Chowdhury Rafiqul Ahsan Department of Microbiology, University of Dhaka, Dhaka, Bangladesh.

\section{Mahmuda Yasmin}

Department of Microbiology, University of Dhaka, Dhaka, Bangladesh.

\section{Jamalun Nessa}

Department of Microbiology, University of Dhaka, Dhaka, Bangladesh.

\section{Correspondence:}

Fahareen-Binta-Mosharraf

Lecturer, Microbiology program Department of Mathematics and Natural Sciences BRAC University, 66 Mohakhali Dhaka,

Bangladesh

\section{An appraisal of Bacteriophages as Biocontrol Agent in Treating E.coli 0157:H7 Mediated Experimental Gastroenteritis in Mice}

\author{
Fahareen-Binta-Mosharraf, Chowdhury Rafiqul Ahsan, Mahmuda \\ Yasmin, Jamalun Nessa
}

\begin{abstract}
The emergence of new pathogenic bacteria resistant to most, if not all, currently existing antimicrobial agents has become a serious problem in modern medicine, particularly because of the affiliated increase in immunosuppressed inhabitants worldwide. The recent surfacing of E. coli O157:H7 as a foremost food pathogen is a lively reminder of its dynamic character. Mounting concerns about drug-resistant pathogenic bacteria have rekindled interest in alternative treatments of bacterial infections. Prominent among these alternatives is phage therapy for combating supportive infections. This observation particularly calls for the in vivo examination of environmental phage candidates to treat stx $1 \mathrm{~A}$ and stx $2 \mathrm{~A}$ positive Escherichia coli O157:H7 induced experimental diarrhea. Two O157-specific lytic bacteriophages PAH6 and P2BH2 were isolated from sewage and characterized. Healthy conventional Swiss albino mice were used for investigating the O157:H7 specific diarrhea applied through three alternative routes (oral, intramuscular and intraperitoneal).The highest titer of orally added E. coli 0157:H7 was found to be fatal within $24 \mathrm{hrs}$. A single oral dose of phage strain $\left(1 \mathrm{X} 10^{7} \mathrm{PFUml}^{-1}\right)$ alone or in combination was sufficient to rescue $100 \%$ of the animals from this lethal challenge in vivo. Finally, the results obtained in this study suggest that cocktail of two coliphages applied orally for treatment gastrointestinal infection have good therapeutic potential.
\end{abstract}

Keywords: Escherichia coli O157:H7 infection, streptomycin treated murine model, phage therap

\section{Introduction}

The World Health Organization (WHO) estimates that 5 million children die each year as a consequence of acute diarrhea. Escherichia coli are the third significant cause of childhood diarrhea in developing countries and are also the most prominent cause of diarrhea in travelers' to underdeveloped countries according to Bru“ ssow et al. 2004. In 1983, Riley and associates reported (Riley et al. 1983) two restaurant outbreaks of hemorrhagic colitis, an enteric disease caused by $E$. coli $0157: \mathrm{H7}$, that was more suggestive of acute mechanical lower gastrointestinal bleeding or inflammatory bowel disease than infection .Due to the flexible genetic character, $E$. coli has one of the widest spectra of disease among any bacterial species. The recent emergence of E. coli $\mathrm{O} 157$ as a major food pathogen is a reminder of its dynamic character.

The pathogenicity of E. coli $0157: \mathrm{H} 7$ is associated with several virulence factors including shiga toxins or verotoxins 1 and 2 (encoded by genes stx) and stx2. The ability to adhere to the intestinal mucosa by intimin (encoded by the eaeA gene) and the production of haemolysin (encoded by the hlyA gene) which lyses erythrocytes, would release heme and haemoglobin that enhance the growth of E. coli $0157: \mathrm{H} 7$ and that could serve as a source of iron (Nataro et al. 1998).

The major virulence factor, and a defining characteristic of EHEC, is the production of Shiga toxin. This potent cytotoxin is the factor that leads to death and many other symptoms in patients infected with EHEC (O'Flynn et al. 2004). Intimin is a 94- to 97-kDa outer membrane protein encoded by eae (which stands for $E$.coli attaching and effacing). Intimin is the only potential E. coli $\mathrm{O} 157$ adherence factor that has been demonstrated to play a role in intestinal colonization in vivo in an animal model (McKee et al. 1996 and Kaper et al. 1998).

Regrettably E. coli O157:H7 infections through natural source do not confer immunity and no vaccine is available yet to provide protection against this pathogen explained by Alam et al. 2011, but a number of experimental approaches are being investigated in animals. The concept of phage therapy to treat bacterial infections was born with the discovery of the bacteriophage almost a century ago. It is now realized that phages play an important role in ecology by 
cycling of organic matter in global level, by evolution of new bacterial genome to transform bacterial pathogenicity and by providing potential tools to face antibiotic resistance crisis in nature (Chennoufi et al. 2004). The bactericidal activity of bacteriophages has been used to treat human infections for years as an alternative or a complement to antibiotic therapy. The use of bacteriophages in controlling bacterial infections are presented, some of which show therapeutic promise. However, it is also quite clear that the safe and controlled use of phage therapy will require detailed information on the properties and behavior of specific phage-bacterium systems, both in vitro and especially in vivo. In vivo susceptibility of bacterial pathogens to bacteriophages is still poorly understood and future research on more phagebacterium systems has to be undertaken to define the requirements for successful phage treatments.

\section{Materials and Methods}

\subsection{Bacterial strain and bacteriophages:}

In this study, E. coli O157:H7 (clinical strain) obtained from ICDDR, B (International Center for Diarrheal Disease Research) was used. The bacteriophage PAH6 and P2BH2, isolated from hospital sewage and infectious to $E$. coli O157:H7 strains with high specificity and lytic activity Alam et al. 2011, was employed as the predator for E.coli O157:H7. The infectivity of bacteriophages PAH6 and P2BH2 against E.coli O157:H7 was re-confirmed by following method of Griffith et al.2003.

\subsection{Molecular characterization of $E$. coli $0157: H 7$ and phage NA (Polymerase Chain Reaction)}

Bacterial chromosomal DNA was extracted and purified according to GuSCN DNA extraction method (Khan et al. 2003, Sharma et al. 2000) to detect the presence of stx1A and stx 2A. Phenol chloroform extraction method was adapted (March et al. 2004) for the preparation of high titer large stocks of lytic phages for nucleic acid extraction.

Polymerase Chain Reaction based detection of stx $1 \mathrm{~A}$ and stx2A gene from extracted DNA of bacteria was performed by following the method of Brown T.A (2006). PCR was performed in a thermal cycler with program required for each system.

Extracted DNA from Escherichia coli O157:H7 NCTC 12079 was used as positive control to detect the presence of stx 1 and stx 2. One hundred base pair DNA (Invitrogen, Cat No: 15628-050) was used as marker to measure the molecular size of the amplified products.

\subsection{Establishment of minimum lethal dose (MLD) of} E.coli 0157:H7 for murine model through appropriate route of administration

One hundred and eight Swiss albino mice (Mus musculus) of 6-8 weeks age was purchased from Animal Division of ICDDR,B. Mice were weighed individually on day 0 and a common body weight was recorded as $18 \mathrm{~g}$. Heart beat was noted as 110- 120/minute. Each mouse was examined initially for their state of health including body temperature, appetite condition, and tidiness of fur, eye health and activity level. The mice were randomly selected on the basis of experimental scheme and to verify the reproducibility of the outcome each set of investigation was performed in duplication.

To demonstrate the infective capacity of E. coli O157:H7 in murine model, three sets of mice (set-1, set-2, and set-3) each containing six animals were designed to administer with increasing dose of E. coli O157:H7 culture (from 1x $10^{5}$ to $1 \times 10^{7} \mathrm{CFUml}^{-1}$ ) through three different routes of entry: oral, intramuscular (i.m.) and intraperitoneal (i.p.). Over the course of infection the animals were observed daily for their activity level, water intake and amount of food consumption (March et al. 2004). All of the three groups of mice (set-1, set-2 and set-1) were starved from feed and water for $24 \mathrm{hrs}$. Treated mice of all the three sets (set 1,2,3) challenged with increasing dose of E. coli 0157:H7 along with the untreated (negative control) ones have been kept under thorough watch for the further $144 \mathrm{hrs}$ to detect any visible change.

\subsection{Confirmation procedure of Escherichia coli 0157:H7 isolated from fecal and blood sample}

To verify if the cause of death was truly due to $E$. coliO157:H7 bacteremia, blood samples were collected from dead mice by cardiac puncture and then directly spread on CT-SMAC plate. Freshly voided fecal samples were collected over time along with the progression of disease symptoms and also spread on CT-SMAC plate (Merril et al. 1996).

Presumptive isolation of E. coli $0157: \mathrm{H} 7$ in both fecal and blood sample is done by direct plating of serially diluted fecal and blood sample onto CT-SMAC and incubated 18-24 hrs at $37^{\circ} \mathrm{C}$. From CT-SMAC plates, suspected colorless $E$. coli $\mathrm{O} 157: \mathrm{H} 7$ isolates were confirmed by cultural properties on EMB and MUG media and by standard biochemical tests.

\subsection{Phage (PAH6 and P2BH2) toxicity test in murine model}

The toxicity of phages (PAH6 and P2BH2) and control suspensions for mice was investigated by treatment of 18 mice with various doses $(100 \mu \mathrm{l}, 200 \mu \mathrm{l}$ and $400 \mu \mathrm{l})$ of PAH6 and $\mathrm{P} 2 \mathrm{BH} 2$ individually through three different routes (oral, intramuscular and intraperitoneal) along with three untreated control group. The mice were observed for signs of illness, and temperatures were taken hourly during the first $5 \mathrm{~h}$ after infection and then daily during the next four days (Soothill 1992 and Soothill et al. 1988).

\subsection{Treatment of mice infected with E.coli 0157:H7 at lethal dose by PAH6 and P2BH2 phages}

Mice were divided into three sets (set-1, set-2, and set-3) each containing five animals. They were administrated with $100 \mu \mathrm{l}$ of Escherichia coli O157:H7 at lethal dose (1X10 ${ }^{9}$ $\mathrm{CFUml}^{-1}$ ) through oral route of entry.

Bacteria infected rodents were treated by PAH6 and P2BH2 phages. Bacteriophage application was carried out individually or in combination and in several doses following the (Table-1). Furthermore, identical dose applied either individually or combindly was added through different ways i.e. oral, intramuscular (i.m.) and intra-peritoneal (i.p.). Over the course of infection, the animals were kept under observation for their symptoms, activity level, water intake and amount of food consumption.

Each set of animals were divided and labeled into three sub sets $\mathrm{X}, \mathrm{Y}$ and $\mathrm{Z}$ depending on the pattern of application of phages i.e. individually or in combination (Table 1). Three increasing dose of phage suspensions (each containing $1 \times 10^{7}$ $\mathrm{PFUml}^{-1}$ ) was designed in a way that the volume of the second dose contained twofold volume of the first dose to give multiplicities of infection (MOIs) of approximately 0.1 , 0.2, and 0.4 (Huff et al. 2006). 
Table 1: Designing of phage doses for therapeutic purpose

\begin{tabular}{|c|c|c|c|c|}
\hline Animal model & Sub set & Group & \multicolumn{2}{|c|}{ Dose plan with PAH6 dose $(\mu \mathrm{l})$} \\
\hline & & A1/B1 & Dose 1 & Positive control $(\mathrm{PBS})$ \\
\cline { 3 - 5 } & & A2/B2 & Dose 2 & $\begin{array}{c}\text { Negative control }\left(10^{9} \mathrm{CFU} / \mathrm{ml}\right. \\
\text { of E.coli O157:H7 })\end{array}$ \\
\cline { 3 - 5 } $\begin{array}{c}\text { Mice set-1 oral infected with } \\
\text { E.coli O157:H7 }\left(1 \mathrm{X} 10^{9} \mathrm{CFU} / \mathrm{ml}\right)\end{array}$ & \multirow{3}{*}{ Sub set X } & A3/B3 & Dose 3 & 100 \\
\cline { 3 - 5 } & & A4/B4 & Dose 4 & 200 \\
\cline { 3 - 5 } & & A5/B5 & Dose 5 & 400 \\
\hline
\end{tabular}

\begin{tabular}{|c|c|c|c|c|}
\hline Animal model & Sub set & Group & \multicolumn{2}{|c|}{ Dose plan with P2BH2 (Volume in $\mu 1)$} \\
\hline \multirow{4}{*}{$\begin{array}{c}\text { Mice set-1 oral infected with } \\
\text { E.coli O157:H7 (1X10 } \mathrm{CFU} / \mathrm{ml})\end{array}$} & \multirow{3}{*}{ Sub set Y } & A1/B1 & Dose 1 & Positive control (PBS) \\
\cline { 3 - 5 } & & A2/B2 & Dose 2 & $\begin{array}{c}\text { Negative control(10 } \mathrm{CFU} / \mathrm{ml} \\
\text { of E.coli O157:H7 })\end{array}$ \\
\cline { 3 - 5 } & & A3/B3 & Dose 3 & 100 \\
\cline { 3 - 5 } & & A4/B4 & Dose 4 & 200 \\
\cline { 3 - 5 } & A5/B5 & Dose 5 & 400 \\
\hline
\end{tabular}

\begin{tabular}{|c|c|c|c|c|}
\hline Animal model & Sub set & Group & \multicolumn{2}{|c|}{$\begin{array}{c}\text { Combined dose of PAH 6 and P2BH2 } \\
(\text { Volume in } \mu \mathrm{l})\end{array}$} \\
\hline \multirow{4}{*}{$\begin{array}{c}\text { Mice set-1 oral infected with } \\
\text { E.coli O157:H7 }\left(1 \mathrm{X} 10^{9} \mathrm{CFU} / \mathrm{ml}\right)\end{array}$} & \multirow{4}{*}{ Sub set Z } & A1/B1 & Dose 1 & Positive control (PBS) \\
\cline { 3 - 5 } & & A2/B2 & Dose 2 & $\begin{array}{c}\text { Negative control(10 } \mathrm{CFU} / \mathrm{ml} \\
\text { of E.coli O157:H7 })\end{array}$ \\
\cline { 3 - 5 } & & A3/B3 & Dose 3 & 100 \\
\cline { 3 - 5 } & A4/B4 & Dose 4 & 200 \\
\cline { 3 - 5 } & A5/B5 & Dose 5 & 400 \\
\hline
\end{tabular}

\subsection{Determination of the potency of phage therapy among} different routes against $E$. coli O157:H7 in murine model Each set of mice was treated with phage (PAH6 and P2BH2) suspension individually and in cocktail was monitored to determine the most effective way by which the phage may exert their potential bacteriolytic activity.

The kinetics of phage potency were investigated for 96 hours by average blood and fecal count $\left(\mathrm{CFUml}^{-1}\right)$ for each way of inoculation at varied time points of post phage treatment based on the clinical status of individual animal. Clinical feature of the untreated and treated mice were monitored as well. E.coli $\mathrm{O} 157: \mathrm{H} 7$ presence was confirmed from both fecal and blood sample on the basis of cultural and biochemical criteria following Fujisawa et al 2000.

\section{Result}

\subsection{Confirmation of $E$. coli O157:H7}

The clinical strain of Escherichia coli O157:H7 was confirmed by direct culture onto Sorbitol MacConkey Agar plate (SMAC) containing cefixime and potassium tellurite (CT-Supplement) where E. coli 0157:H7 produced colorless colonies according to multiple scientific researches. (Bell et al. 1994, March and Ratnam 1986 )

Colorless colonies from CT-SMAC plate were inoculated in MUG broth where E. coli 0157:H7 showed MUG (4methylunbelliferyl-b-D-glucuronide) negative growths (E.C. Broth with MUG; Oxoid; England) after exposure to $360 \mathrm{~nm}$ UV light.

\subsection{Confirmation of PAH6 and P2BH2 infectivity against E.coli O157:H7}

Plaques of phage PAH6 and $\mathrm{P} 2 \mathrm{BH} 2$ were isolated against $E$. coli O157:H7 bacterial lawn and later size, shape, margin and transparency of the plaques were thoroughly investigated (Fig 1 and 2). Most of these plaques against E. coli O157:H7 were tiny, fuzzy and very few were found to have sharp rim.

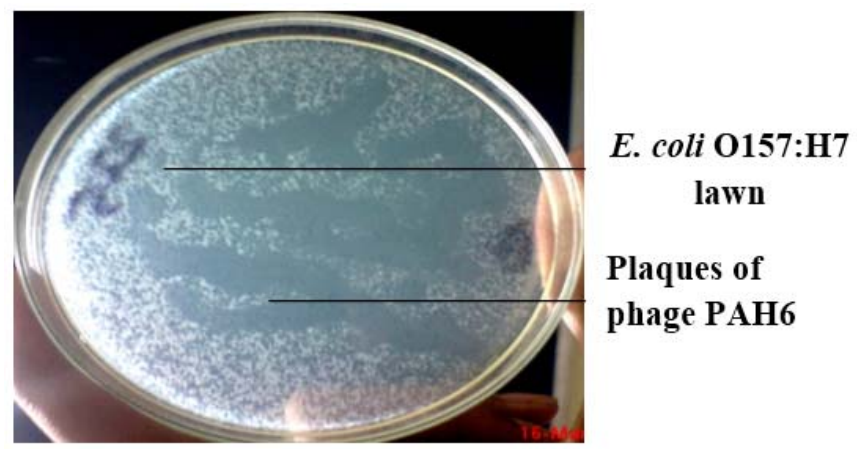

Fig 1: Plaques of phage PAH6 on E. coli O157:H7 lawn

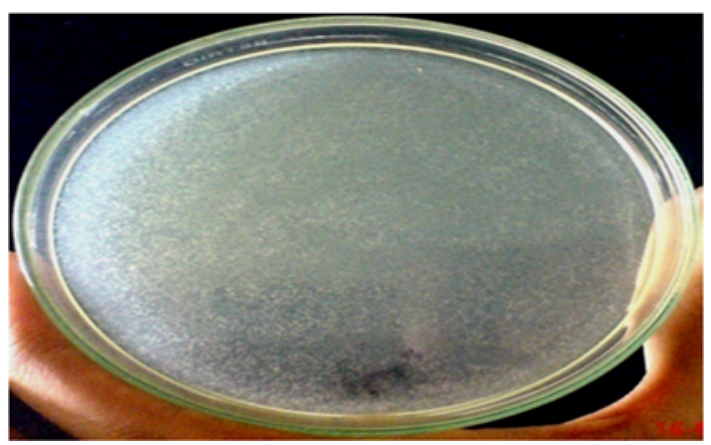

Fig 2: Bacteriolytic activity of $\mathrm{P} 2 \mathrm{BH} 2$ against E. coli $\mathrm{O} 157: \mathrm{H} 7$

3.3 Detection of $E$. coli $0157: H 7$ and phage specific virulence genes by PCR

The result revealed that clinical strain of E. coli $\mathrm{O} 157: \mathrm{H} 7$ used in the research was positive for stx1A (348bp) and stx2A (584 bp) whereas both phages (PAH6 and P2BH2) used in this research were negative for stx $1 \mathrm{~A}$ and $s t \times 2 \mathrm{~A}$ after 35 cycles of amplification followed by agarose gel electrophoresis.

3.4 Determination of minimum lethal dose (MLD) of E.coli 0157:H7 through appropriate route of administration

The diseased, moribund and deceased condition of mice was recorded according to Table 2 at various time points after 
bacterial inoculation (in increasing dose) in a six day long experimentation. The disease severity of mice was found to be correlated with the augmented dose of E.coli O157:H7. This observation was shared by all the three routes of bacterial inoculation. However, the oral way of E.coli O157:H7 addition at a dose of $1 \mathrm{X} 10^{9} \mathrm{CFU} \mathrm{m}{ }^{-1}$ was proved to the most potent in developing bacterial pathogenesis and hence selected as the MLD.

Table 2: Increasing dose of E. coli O157:H7 enhances disease severity

\begin{tabular}{|c|c|}
\hline Disease symptoms & Level of disease severity \\
\hline A normal and unremarkable condition & level 0 \\
\hline Slight illness, defined as lethargy and ruffled fur & Level 1 \\
\hline Moderate illness, defined as severe lethargy, ruffled fur, and hunched back & Level 2 \\
\hline $\begin{array}{c}\text { Severe illness, with all the signs plus exudative accumulation around partially closed eyes } \\
\text { increase body temperature loss of appetite }\end{array}$ & Level 4 \\
\hline A moribund state & Level 5 \\
\hline Death & \\
\hline
\end{tabular}

\subsection{Identification Escherichia coli O157:H7 isolated from} fecal and blood sample

Colorless sorbitol non-fermenting colonies from CT-SMAC plate were streaked on EMB plate shown green metallic sheen were selected for further identification by biochemical tests. The targeted colonies were also incubated in MUG broth for detection of non-fluorescence after exposure to UV light.

\subsection{Phage (PAH6 and P2BH2) toxicity test in murine model}

All fifteen mice retained as normal condition upon treatment with phages during the four days observation period similar to the three control group.

\subsection{Exploring the suitable route of administration of phages in E. coli 0157:H7 infected murine model}

In case of either individual or combined phage treatment in E.coliO157:H7 infected mice through three alternative routes (i.e. oral, intramuscular and intraperitoneal), clinical status of the mice was recorded and fecal samples were collected at different time points up to $96^{\text {th }} \mathrm{hr}$ post phage treatment. However, bacterial count in blood was examined at $96^{\text {th }} \mathrm{hr}$ only for the highest phage dose applied and compared with the blood of healthy control group which was free from any visible contamination.

E.coli $\mathrm{O} 157$ infected mice treated orally with increasing doses (dose 3, 4, 5) of phage individually (PAH6 or P2BH2) or in combination (PAH6 and $\mathrm{P} 2 \mathrm{BH} 2$ ) developed minor symptoms with time but mice receiving different biocontrol doses recovered slowly within one and half days. The gradual decrease in E.coli O157 count in stool was recorded (Fig 3) with the increasing treatment dose for all the three categories of phage treatment when compared with the untreated mice (control) showed in Fig 4.

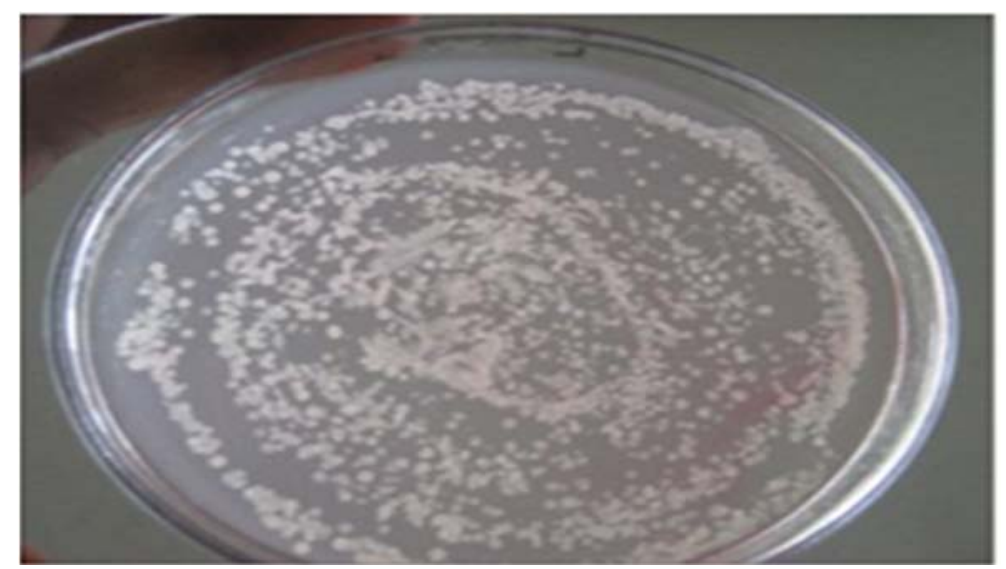

Count of E. coli O157: H7 due to treatment with dose 3 in blood

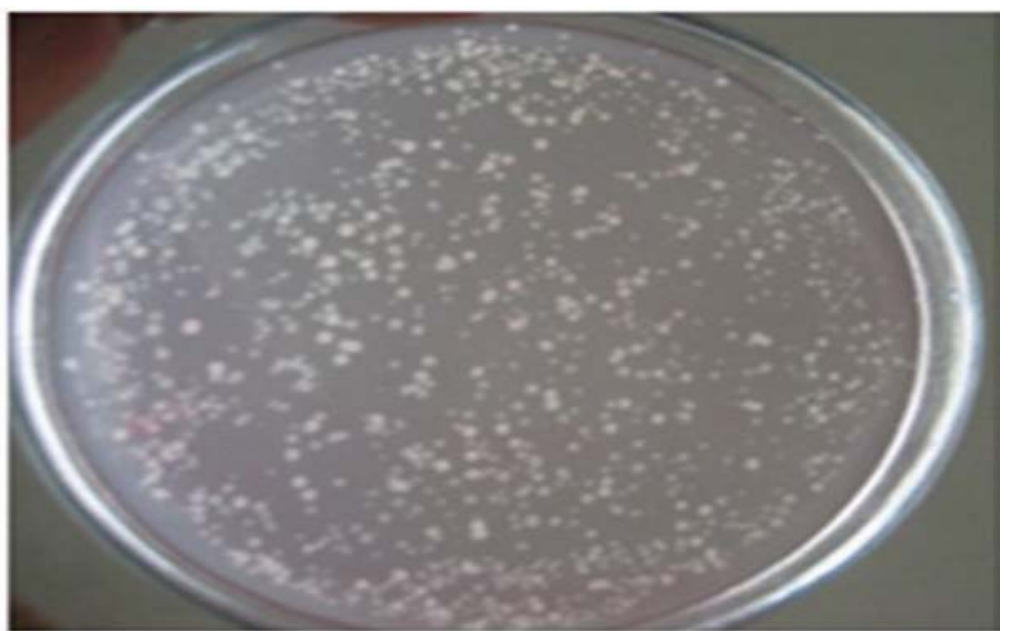

Level of presence of E. coli O157: H7 by treatment with phage PAH6 (dose 4) in blood $\sim 609 \sim$ 


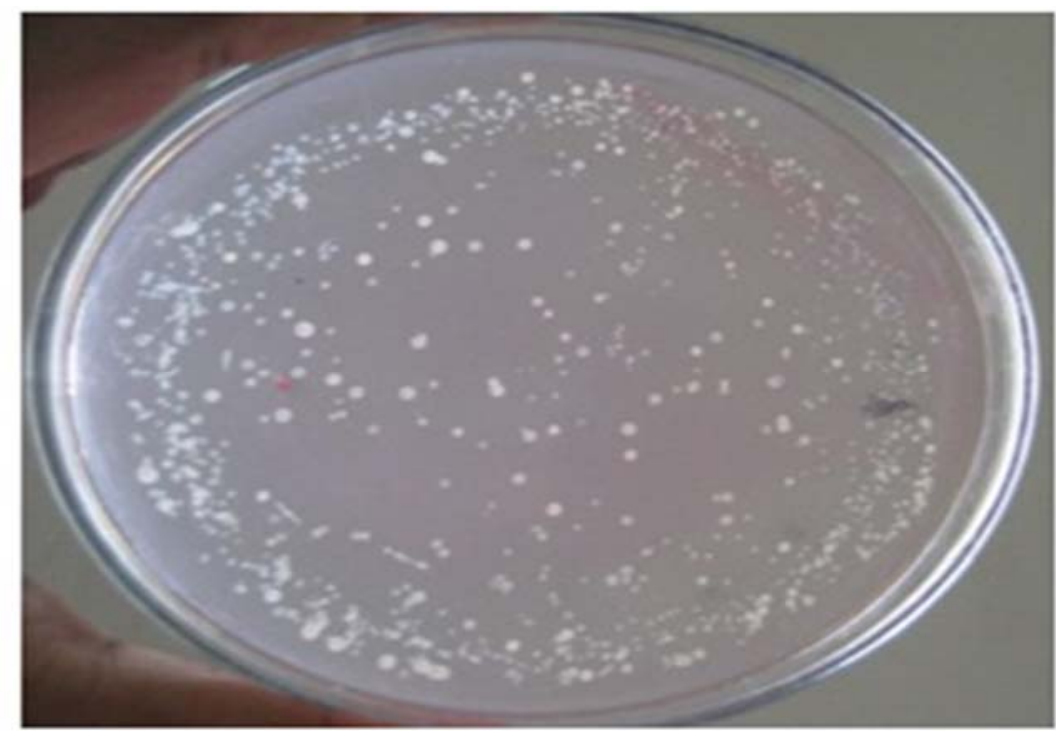

Degree of presence of E. coli O157: H7 due to addition of binary phages (dose 5) in blood

Fig 3: Potency level of three doses of oral phage application in reducing E.coliO157:H7 count in blood sample through oral route at $96^{\text {th }}$ hour post treatment

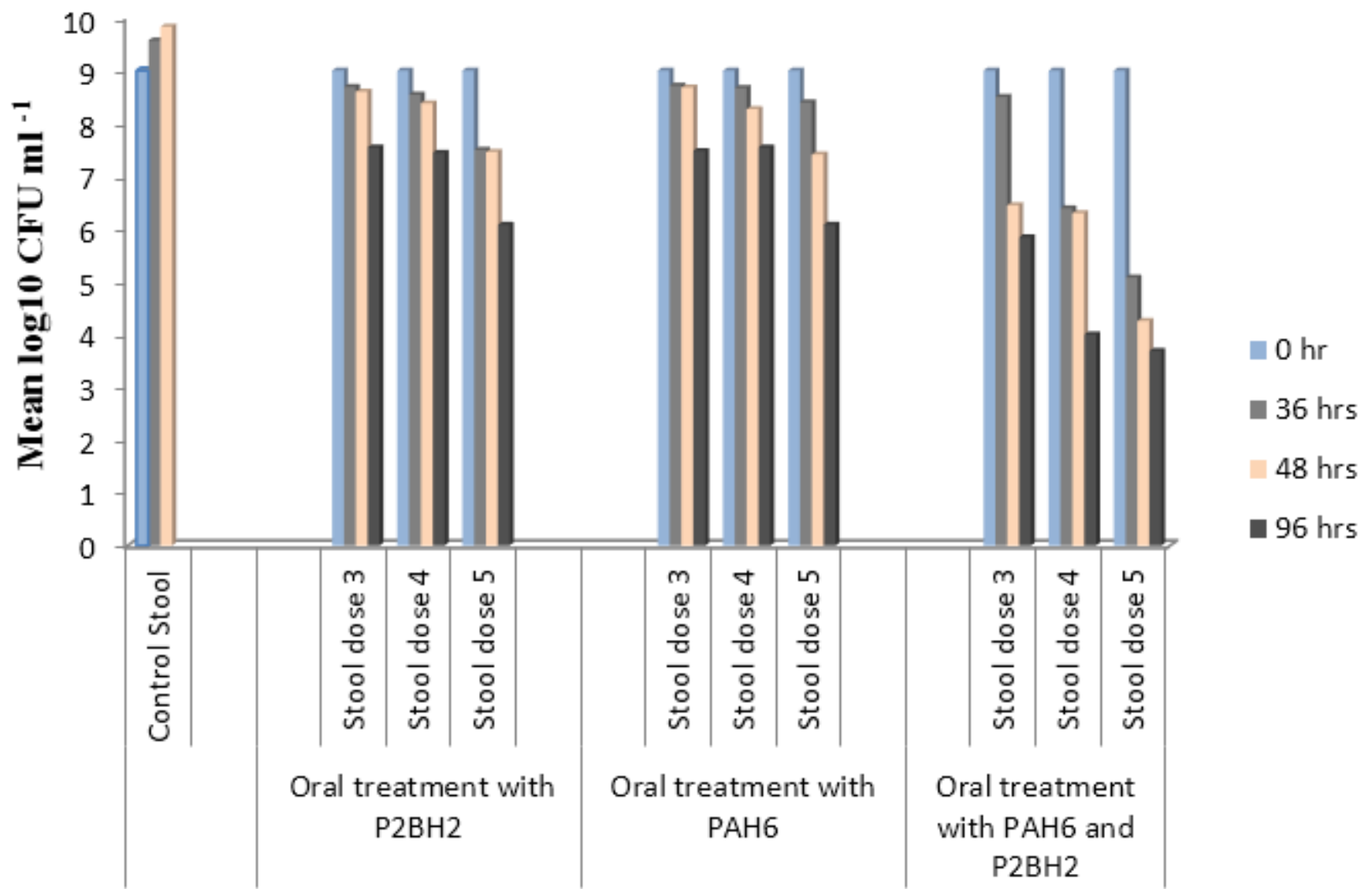

Fig 4: Efficacy of orally administered phages (alone or in cocktail) in treating E.coliO157:H7 infected murine model

Treatment of E.coli O157:H7 infected mice via peritoneal cavity with increasing doses (dose 3, 4, 5) of phage individually (PAH6 or P2BH2) or in cocktail (PAH6 and $\mathrm{P} 2 \mathrm{BH} 2$ ) produced insignificant symptoms with time and they gradually recovered within 36 hours. The steady decline in E.coli O157 count in stool was observed (Fig 5) with the increasing treatment dose for all the three classes of phage treatment when compared with the untreated mice (control).
Mice treated intramuscularly with different doses (dose 3, 4, 5) of test phage either singly (PAH6 or P2BH2) or in cocktail (PAH6 and P2BH2) developed similar pattern of outcome as peritoneal administered therapy. The gradual reduction in stool E.coli O157 number correlated parallely (Fig 6) with the increasing treatment dose both for single or cocktail application. 


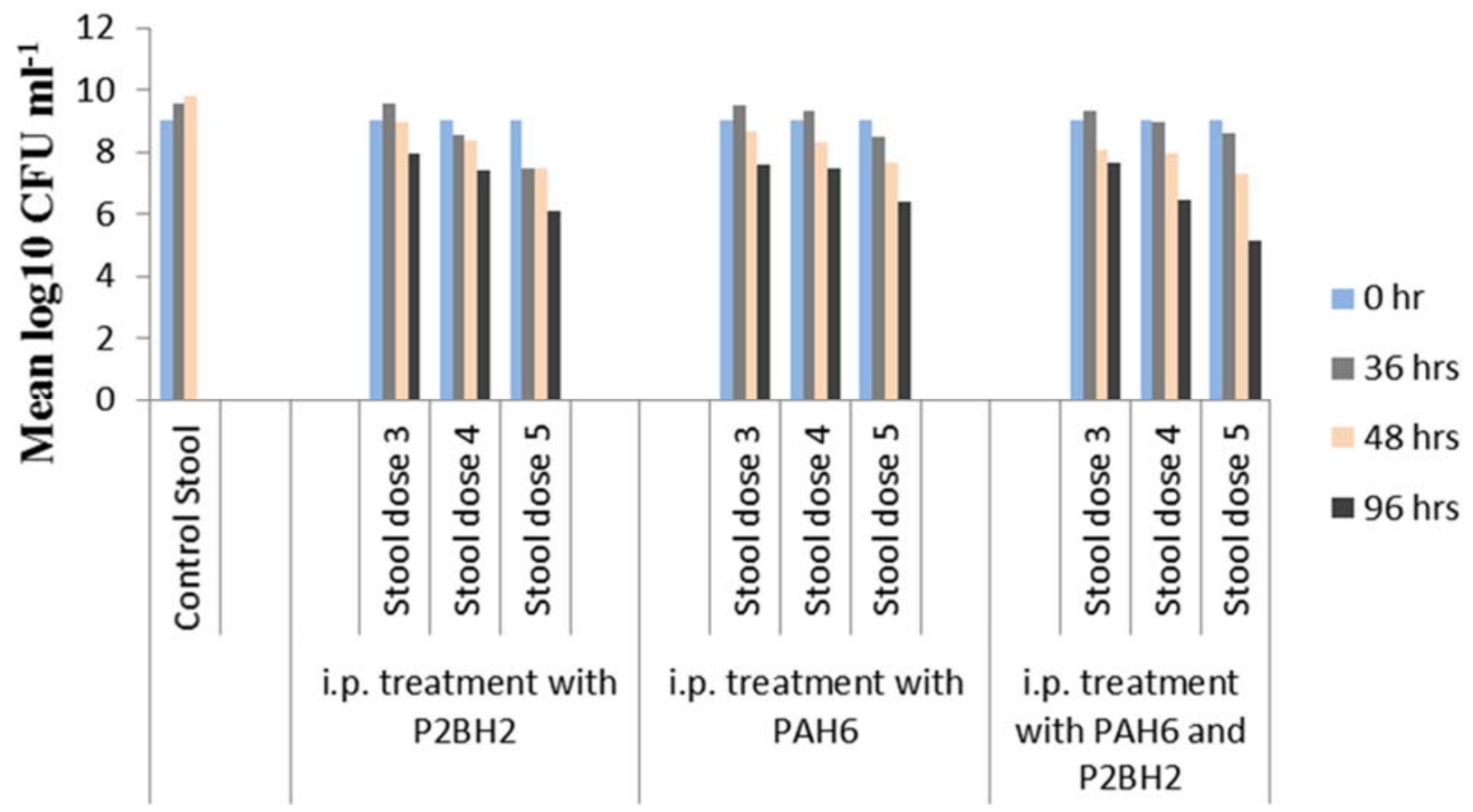

Fig 5: Potency of peritoneally applied phage (alone or in cocktail) as therapeutic agent assessed by fecal and blood E.coliO157:H7 count in mice

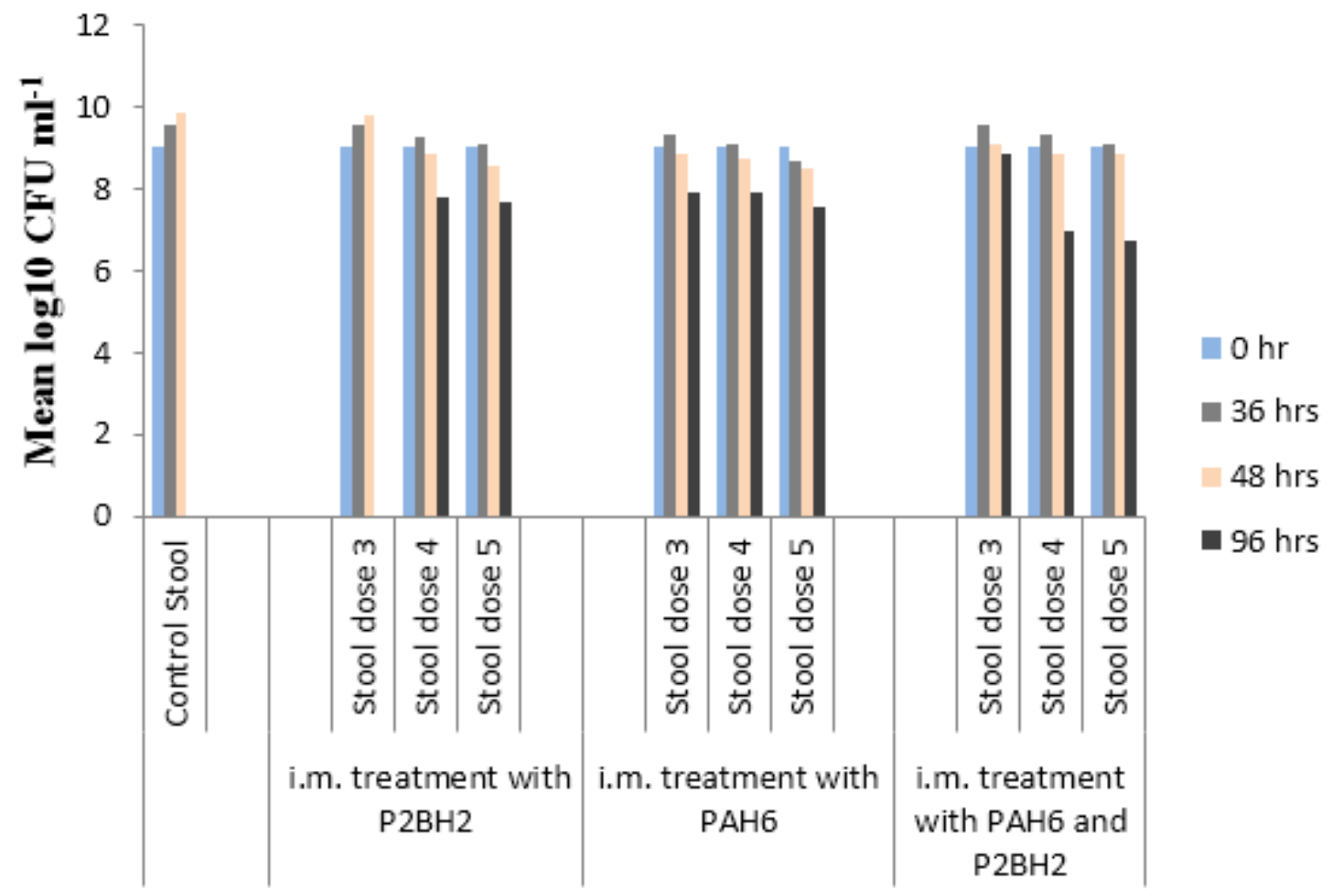

Fig 6: Intramuscularly applied phage (alone or in cocktail) showed different degrees of bacteriolysis evaluated by fecal and blood E.coliO157:H7 count in mice

Mice inoculated with lethal dose of bacteria but without any phage therapy developed severe bacterimia $\left(4.8 \mathrm{X} 10^{9} \mathrm{CFU} \mathrm{ml^{- }}\right.$ $\left.{ }^{1}\right)$ at $48^{\text {th }} \mathrm{hr}$ and developed moribund condition. All category of phage treatment \{individually (PAH6 or $\mathrm{P} 2 \mathrm{BH} 2$ ) or in combination (PAH6 and $\mathrm{P} 2 \mathrm{BH} 2)\}$ in murine model efficiently controlled microbial load in their blood (Fig 4, 5 and 6) except dose 1 of P2BH2 $\left(4.3 \times 10^{9} \mathrm{CFU} \mathrm{ml}^{-1}\right.$ at $48^{\text {th }} \mathrm{hr}$ post treatment). However, the bacterial count was higher in stool than blood when evaluated at the same time point while phage PAH6 and P2BH2 was applied together.
3.8 Comparison of the efficacy of phage therapy among different routes against $E$.coli $0157: H 7$ in murine model From the previous experimentation (Fig 4, 5 and 6), $400 \mu \mathrm{l}$ of phage suspension (MOI 0.4) containing dual phage candidates (i.e. dose 5) showed highest bacteriolytic property. Outputs from the three test routes were compared (Fig7 and 8), and oral way of application was proved to be the most potent for controlling E. coli O157:H7 infection. Here, the control group receiving fatal dose of bacteria but not receiving any biotreatment showed almost fivefold 
increase in microbial growth before reaching moribund condition at $48^{\text {th }}$ hour and being dead. It could be noteworthy to mention that fecal bacterial count in this control group augmented proportionately with the severity of symptoms studied (Fig 7).

The untreated control group of mice receiving lethal dose of E. coli reached moribund condition at $48^{\text {th }}$ hour (bacterial

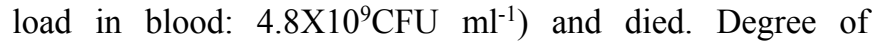
septicemia was estimated for dose 5 introduced into these infected animals beforehand (Fig 8) and while was compared here, four log decrease of E.coli O157:H7 was observed for all the three routes under investigation. However, oral way of biocontrol addition was the most potent among these three and intramuscular route showed the least efficiency.

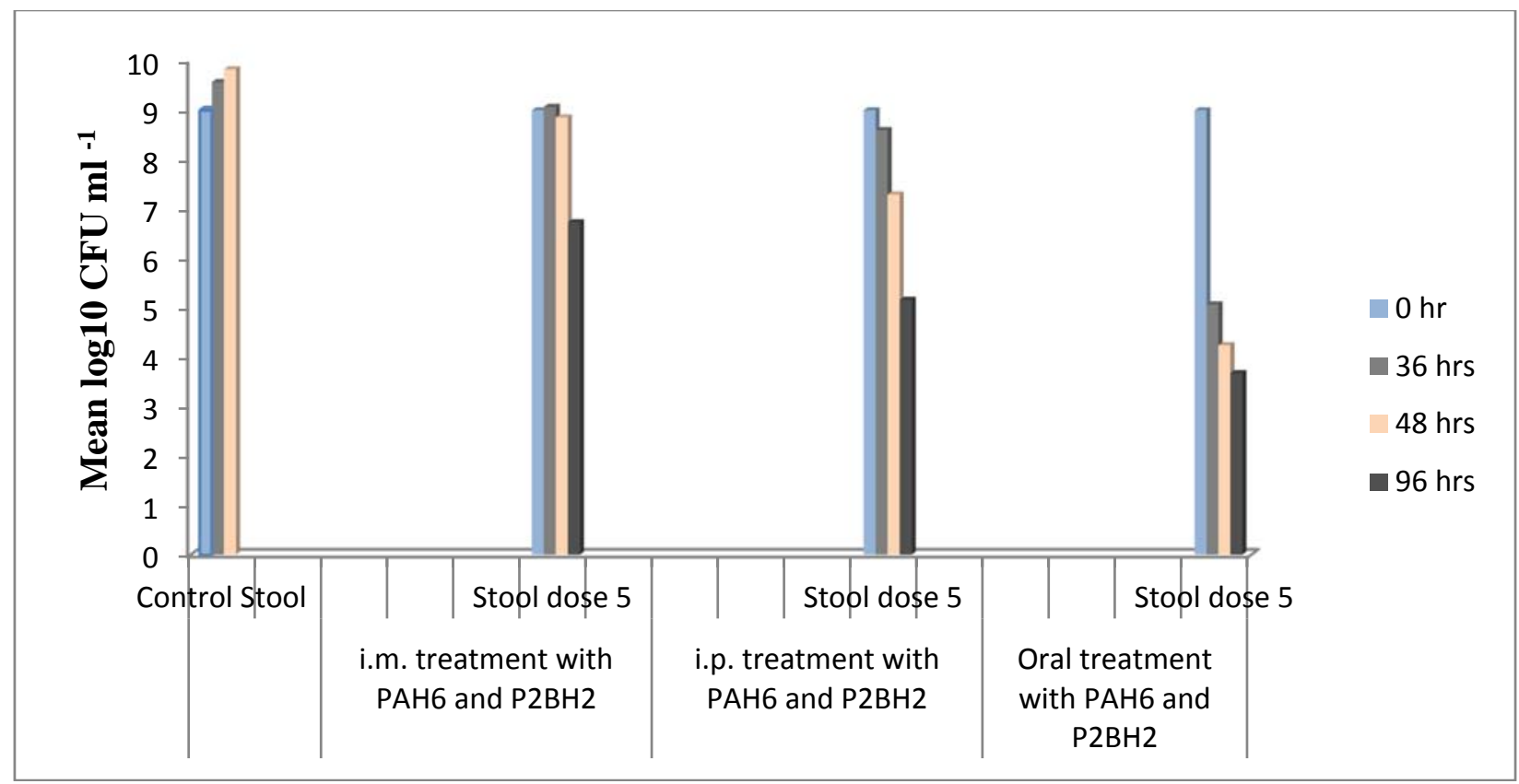

Fig 7: Comparison among the efficiency of the three alternate routes of biocontrol application assessed by fecal E.coli O157:H7 count in mice

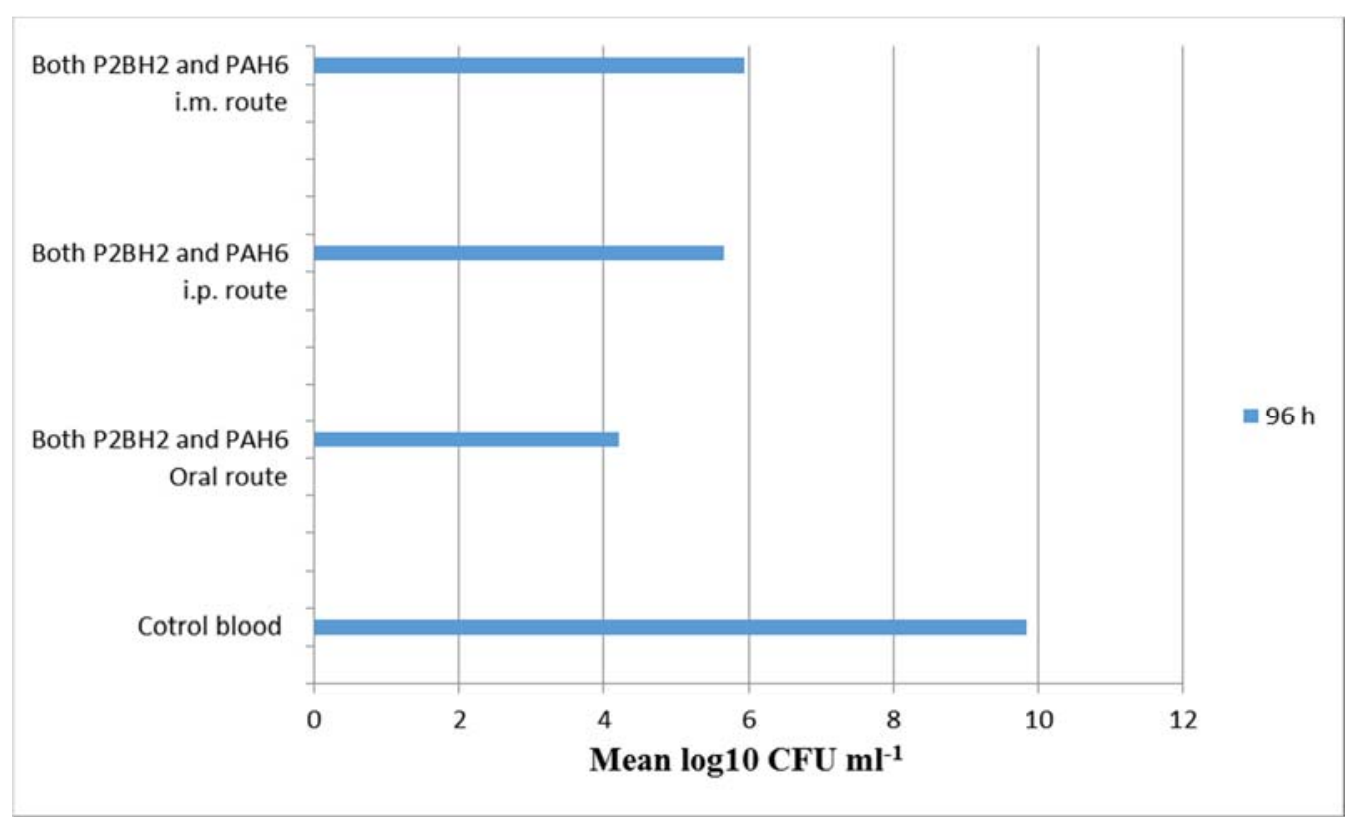

Fig 8: Competence of the three test routes of phage application assessed by E.coliO157:H7 count in murine blood

\section{Discussion}

One of the wonder discoveries of the 20th century is no doubt the finding of antibiotics. This is obvious, but the genuine speculation is the rise of antibiotic resistance in hospitals, communities, and the environment concomitant with their use. The surprising genetic capacities of microbes have benefitted from man's overuse of antibiotics to exploit every source of resistance genes and every means of horizontal gene transmission to develop multi-resistant newly emerged pathogens.

Enterohaemorrhagic Escherichia coli (EHEC) are a worldwide cause of infection in humans and animals. Since
E. coli $\mathrm{O} 157: \mathrm{H} 7$ was identified in 1983, it has materialized as an important human pathogen and found to be associated with outbreaks and sporadic cases throughout the world. Outbreaks have been attributed to food, water, and person-toperson and direct fecal contact (O'Flynn et al. 2004 and Akashi et al. 1990). The potent cytotoxin (Shiga toxin) is the factor that leads to many other symptoms and death in patients infected with EHEC.

Effectual treatment and prevention measures are lacking for E. coli diarrhea. The primary basis of treatment is oral rehydration. Antibiotic use is of doubtful value since 
resistance is widespread among E. coli, and vaccines are still in the early development phase (Bru“" ssow et al. 2004).

The utilization of bacteriophages as a realistic approach to the control of pathogens has attracted considerable interest in recent years because of the global emergence of multiple antibiotic resistant bacteria. Phage therapy has been used successfully since the early 1920 s, but this has been largely confined to regions within the former Soviet Union (O'Flynn et al. 2004). The life cycle of lytic bacteriophage being selfreplicating and self-limiting makes them attractive as a natural and safe alternative to antibiotics to treat bacterial diseases (Bru" ssow et al. 2004).

Our scientific research showed renewed interest in phage therapy. Part of this interest stems from a series of spectacular experiments conducted with toxin free host specific viable phages applied in animal model as antibacterial agents. The study concerns the exploitation of two distinct wild type lytic phages (PAH6 and P2BH2) isolated from raw sewage as biocontrol agents to eliminate the pathogen E. coli O157:H7, a clinical strain obtained from ICDDR,B (International Center for Diarrheal Disease Research). These phages were selected for their plaque size (Fig1 and 2), clarity of plaques and wider host range (O'Flynn et al. 2004).In our research, stx1A and stx2A gene negativity in our two isolates mark them as safe and potent candidate to be applied in phage therapy.

Healthy conventional Swiss albino mice were used for investigating the clinical manifestation exerted by stx $1 A$ and stx2A positive E. coli $\mathrm{O} 157$ in various doses applied through three alternative routes (oral, intramuscular and intraperitoneal) of inoculation. Oral route provoked disease severity earlier and of greater degree than the others. The orally infected mice died near $48^{\text {th }}$ hour whereas mice inoculated by i.m. or i.p. ways developed experimentally induced gastroenteritis but recovered by 72 hours. Hence ,the oral way of E.coli O157:H7 addition at the dose of $100 \mu \mathrm{l}$ suspension containing $1 \times 10^{9} \mathrm{CFU} \mathrm{m}{ }^{-1}$ was taken as the most potent concentration in producing bacterial fatality and hence selected as the MLD. Tanjii and coworkers had also used the same dose to cause fatality in murine models (Tanji et al. 2005).

The two test coliphages were introduced through the three alternative routes (oral, intramuscular and intraperitoneal) in murine model infected with E.coli O157:H7 at a lethal dose. On the basis of clinical stand point, phages appeared to be completely innocuous to the experimental healthy rodents in this work. In our study, doses were designed in a way (Table 2) that different doses contained $10^{7} \mathrm{PFU} \mathrm{m}{ }^{-1}$ with MOI of $0.1,0.2$ and 0.4. Among these, phage dose with MOI of 0.4 was found to decrease bacterial load in feces efficiently.

The control group of animals had orally received lethal dose (100 $\mu$ l containing $1 \times 10^{9} \mathrm{CFUml}^{-1}$ ) of E. coli O157:H7 at zero hour but not treated with phage developed severe symptoms and died by 48 hours post infection. The test lytic phages, PAH6 or $\mathrm{P} 2 \mathrm{BH} 2$ individually reduced bacterimia \{PAH6 (almost 3 log decrease) and P2BH2 (2 log decrease)\} in mice and had rescued them from lethal challenge. Four log decline (Figure 7) of the pathogen in blood was documented after addition of binary phage (i.e. PAH6 and P2BH2 together) suspension and that indicates the more potent lytic ability of combined applied phages.

The presence of E. coli O157:H7 level found in the feces (Fig 4) and blood samples collected from phage treated mice at various time points was proportionately correlated to their health status. This observation was shared by all the three test routes of phage administration as depicted in Fig 5 and 6. All classes of phage treatment individually or in combination in murine model efficiently inhibited bacterimia (Fig 8) but could not eliminate the pathogen in blood. Reduction in septicemia was the highest at dose 5 (phage cocktail, MOI $0.4)$ when applied through any of the three test routes. It could be noteworthy to include that $100 \%$ of these phage treated animals were rescued back to normal health by 48 hours. Animal immune system is continually fighting against pathogens. Our observations coincide with other works where it has been suggested that phage application may decrease the number of infecting bacteria to a level from where the host defense can take over and clear the remaining bacteria (Levin et al .2004 and Lemuel et al.2004).

There are scores of technological challenges of phage therapy that need to be looked into before making universal policy for commercially available phage products. Research on different aspects of phage therapy can facilitate the evolution of standardized phage banks having a comprehensive library of therapeutically approved lytic phages. These could no doubt assist in initiating phage therapy immediately after the identification of would be emerged pathogens in future.

\section{References}

1. Akashi, S., Joh, K., Tsuji, A. 1990. A severe outbreak of haemorrhagic colitis and haemolytic uraemic syndrome associated with Escherichia coli 0157:H7 in Japan. Eur J Pediatr.153 (9):650-655.

2. Alam, M., Farzana, T., Ahsan, R.C., Yasmin, M., and Nessa, J. 2011. Distribution of coliphages against four $E$. coli virotypes in hospital originated sewage sample and a sewage treatment plant in Bangladesh. Indian. J. Microbiol. 51(2):188-193.

3. Bell, B. P., Goldoft, M., Griffin, P. M. , Davis, M. A., Gordon, D.C., Tarr, C.A., Lewis, B., Barrett, T. J., Wells, J. G. 1994. A multistate outbreak of Escherichia coli O157:H7-associated bloody diarrhea and hemolytic uremic syndrome from hamburgers. The Washington experience JAMA. 272: 1349-1353.

4. Bru" ssow, H., C. Canchaya, W.D. Hardt. 2004. Phages and the evolution of bacterial pathogens: from genomic rearrangements to lysogenic conversion. Microbiol. Mol. Biol. Rev. 68 (3): 560-602.

5. Brown, T.A. 2006. Gene Cloning and DNA Analysis: An Introduction. $5^{\text {th }} \mathrm{Ed}$.

6. Chennoufi, C.S., Anne, B., Marie-Lisc, D. and Harald, B. 2004. Phage-Host interraction : an ecological perspective. J. Bacteriol. 186(12): 3677-3686.

7. Doyle, M. P. and Meng, J. 1998. Microbiology of Shiga toxin-producing Escherichia coli in foods, in Escherichia coli O157:H7 and Other Shiga Toxin-Producing E. coli Strains. J. B. Kaper and A. D. O'Brien, Eds., pp. 92-108, ASM Press, Washington, DC, USA.

8. Fujisawa, T., S. Sata, K. Aikawa, T. Takahashi, T. Shimada and S. Yamai. 2000. Modification of Sorbitol MacConkey medium containing cefixime and tellurite for isolation of Escherichia coli $\mathrm{O} 157: \mathrm{H} 7$ from radish sprouts. Applied and Environmental Microbiology. 66(7): 3117-3118.

9. Griffiths, W.M., Goodridge, L. and Gallaccio, A. 2003. Morphological, host range, and genetic characterization of two coliphages. Appl. Environ. Microbiol. 69(9):5364-5371. 
10. Huff, W. E., Huff, G. R., Rath, N. C., and Donoghue, A. M. 2006. Evaluation of the Influence of Bacteriophage Titer on the Treatment of Colibacillosis in Broiler Chickens. Food and agricultural organization of the United Nations. 85(8):1373-1377.

11. Kaper, J.B., Elliott, S., Sperandio, V., Perna, N.T., Mayhew, G.F. and Blattner, F.R. 1998. Attaching and effacing intestinal histopathology and the locus of enterocyte effacement. In Escherichia coli and other Shiga toxin-producing E. coli strains. Kaper JB, O'Brien AD eds. Washington DC, ASM Press. 42(3):1382-1383.

12. Khan, A., Simanti, D., Das, S.C., Ramamurthy, T., Khanam, J., Takeda, Y., Bhattacharya, S.K. and Nair, G.B. 2003. Shiga toxin producing Escherichia coli infection: current progress \& future challenges. Ind. J. Med. Res. 118: 1-24.

13. Lemuel, B. R. N., Remedios, S., Flamiano, M.S.2004. Use of Bacteriophages as Therapy for Escherichia coliInduced Bacteremia in Mouse Models. Phil J Microbiol Infect Dis 33(2):47-51.

14. Levin, B. R. \& Bull, J. J. 2004. Population and evolutionary dynamics of phage therap. Nature Reviews Microbiology. 2:166-173.

15. March, S. B. and Ratnam, S. 2004. In Vitro and In Vivo Bacteriolytic Activities of Escherichia coli Phages: Implications for Phage Therapy. J.of Clin. Microbiol. 48(7):2558-2569.

16. March, S. B. and Ratnam, S. 1986. Sorbitol-MacConkey Medium for Detection of Escherichia coli0157:H7 Associated with Hemorrhagic Colitis. J. of Clin. Microbiol. 23(5):869-872.

17. McKee, M.L. and O'Brien, A.D.1996.Truncated enterohemorrhagic Escherichia coli (EHEC) O157:H7 intimin (EaeA) fusion proteins promote adherence of EHEC strains to HEp-2 cells. Infect. Immun. 64(6): 2225-2233.

18. Merril, C. R., Biswas, B., Carlon, R., Jensen, N. C., Creed, G. J., Zullo, S., and Adhya, S. 1996. Longcirculating bacteriophage as antibacterial agents. Proc. Natl. Acad. Sci. 93:3188-3192.

19. Nataro, J. P., and Kaper, J. B. 1998. Diarrheagenic Escherichia coli. Clin. Microbiol. Rev. 11: 142-201.

20. O'Flynn, G., Ross, R. P., Fitzgerald, G. F., and Coffey, A. 2004. Evaluation of a cocktail of three bacteriophages for biocontrol of Escherichia coli O157:H7.Appl. Environ. Microbiol70(6):3417-3424.

21. Sharma, K.N., Rees, D.E.C. and Dodd, R.E.C.2000. Development of a Single-Reaction Multiplex PCR Toxin Typing Assay for Staphylococcus aureus Strains. Applied and Environmental Microbiology. 66(4):13471353.

22. Riley, L. W., Remis, R. S., Helgerson, S. D., McGee, J. G., Wells, B. R.,Davis, R. J., Hebert, E. S., Olcott, L. M., Johnson, N. T., Hargrett, P. A.and Cohen, M. L. 1983. Hemorrhagic colitis associated with a rare Escherichiacoli serotype. N. Engl. J. Med. 308:681-685.

23. Soothill, J. S., Lawrence, J. C. and Ayliffe, G. A. J. 1988. The efficacy of phages in the prevention of the destruction of pig skin in vitro by Pseudomonasaeruginosa. Med. Sci. Res. 16:1287-1288.

24. Soothill, S.J. 1992. Treatment of experimental infections of mice with bacteriophages. J. Med. Microbiol. 37:258261.

25. Tanji, Y.,Shimada, T., Fukudomi, H.,Miyanaga, K., Nakai, Y., and Unno, H.. 2005. Therapeutic use of phage cocktail for controlling Escherichia coli O157:H7 in gastrointestinal tract of mice. J. Biosci. Bioeng. 100(3):280-7. 